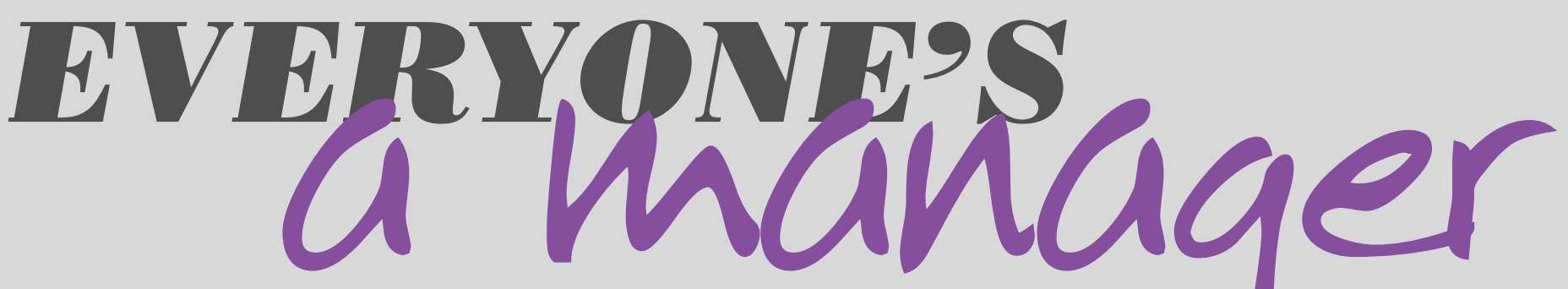

Michael R.Young * says that it is important to appreciate your role in the dental team in the context of the bigger picture.

\section{Hitler and context}

I love history: I enjoy studying past events and objectively analysing patterns of cause and effect. However, I remember studying history at school, when great chunks of the past were simply dished up as stand-alone topics with little or no reference to what had gone before or what happened after. History without context is meaningless. You need to be able to see and understand the bigger picture, which is why I'd prefer to read a biography of Hitler than a chronological narrative of the events of 1938-9 to uncover the causes of the Second World War. Why something happens is, in my opinion, as important as what happens. This is not only true in history but also with everything else in life. But what has history to do with working in a dental practice and with being a manager?

\section{Having a vision}

Learning about or doing anything that is workrelated without understanding the whys and wherefores of what you are doing and why you do it in a certain way is like reading a book but only looking at every other page. You can't possibly hope to see the plot or the story or put anything that happens into context. In the workplace, appreciating your role in the context of how the practice is managed is important, but to do that you have to know what the bigger picture is. This bigger picture to me means knowing not only that the practice has, for example, a vision, objectives, a business plan or a strategic plan, but also that

* Michael has over 20 years' experience of managing a dental practice and taught clinical dentistry at two dental hospitals. He has co-written a book with his wife Linda about how anyone working in a dental practice can develop themselves and become a good manager. The book is provisionally titled Developing your dental team the Genghis Khan way and is due to be published sometime in 2013. you have perhaps had a hand in formulating them. Employee involvement, even employee ownership, is the order of the day, and that means that you have to understand how the business is managed and your role in making it run as effectively and efficiently as possible. In today's business world I believe that everyone has to be a manager.

One of the biggest shake-ups to hit dental practices in the last few years has undoubtedly been the Care Quality Commission (CQC) Outcome 14 which states that, The induction of new staff includes at least the aims, objectives and purpose of the service. Even without this CQC imperative, I believe that employee involvement at all levels of the business of a practice makes sense. It is their involvement and understanding of why things are done that adds context to their work and which ultimately adds perspective to what they do.

\section{What is management?}

First, you need to know what management is. Quite simply it is about planning, organising, implementing, and then reviewing or monitoring the progress of any particular task. You probably subconsciously follow this logical process tens, if not hundreds, of times a day both at work and in your home life without realising it. However, being aware of the management process and using it consciously is the first step along the road to becoming a manager. Second, you need to find out about all of the elements that go into running the practice, which in very broad terms means the management of resources. I don't mean you have to know everything inside out, but it could improve your understanding of the running of the business if you did. It will all help you to see the bigger picture, to put everything into some sort of context, and hopefully turn you into not just a manager, but also into a good manager.

I have written a book about managing a dental practice, but I want to refer to one element from it to use as an example of how and why you should become more involved with running the practice and by extension, the business. That element is the Business Planning Cycle (Fig. 1).

\section{Where are you going?}

Producing what is often called a mission

statement (CQC prefer to call it a 'Statement of Purpose') is the first step in this cycle. Whether you call it a 'mission statement', 'business philosophy', 'business values', 'practice purpose' or 'statement of purpose' is irrelevant; what is important is that it combines the inspiration of where the practice is going and how it is going to get there with the realities of where it is now. The important thing for you as an employee is that you are not just a passenger, you should be helping to steer the business in the right direction. In helping to write a mission statement you need to produce something that refers to aiming to be the best, identifying the importance of people, quality, service and communication.

Perhaps one of the areas in which you can have a real say in the development of the practice is in helping to identify the strengths and weaknesses of the business, and the opportunities and threats that exist for and to it. These provide the evidence for the need for change and improvement within the practice, and help to uncover the core competencies of individuals and of the practice as a whole. Look beyond the obvious.

\section{Strategic planning}

The next stage in the Business Planning Cycle is strategic planning. It asks the key questions: Where is the practice now? How did it get there? What business is it in? Where does it want to be in the future? How is it going to get there? These are things you should be actively involved with and help to manage.

Everything I've mentioned so far now has to be pulled together into a business plan. This is something every practice should have and something that every employee should know something about. A business plan 
should tell the reader something about the background of the practice and its objectives. The reader must then see that the business understands the market in which it is operating, and how it proposes to market its services. The financial health, both current and future, must be included, which means knowing how to draw up a budget and a cash flowchart. In reality both of these are no different from your own personal budget except that the numbers are probably larger and the income and expenditure will be from and on different things. Like you, the business has to balance the books at the end of each month. Understanding and appreciating how to manage a budget and cash flow are fundamental elements in managing any business.

\section{The Business Planning Cycle}

The Business Planning Cycle is something with which I think you should be familiar, and which you should take an active part in helping the practice owner(s) develop. Obviously you may not be privy to everything, but you should understand the principles and rationale behind it.

If a mission statement represents the general direction in which the practice is heading, then the personal and business objectives are a more focused statement of its aims. People often produce woolly or vague objectives; yours must be specific, measurable, agreed, realistic and time-bound (SMART). They must also be positive, challenging and in tune with the business's.

\section{Achieving objectives}

Keeping the practice on course relies on everyone meeting his or her objectives. Your employer should therefore carry out regular performance appraisals during which you can discuss how you are progressing towards achieving your objectives. Appraisals are an excellent way of enabling you to build a good rapport with your employer.

I involved my employees in the day-to-day and the more strategic management of my practice long before it was an obligation under CQC. Now that employees are expected to know much more about the business in which they work it seems that a great opportunity has opened up for them to take a more active role in helping to shape the practice, the way it is managed, and for them to personally improve their managerial knowledge and skills. Enlightened employers should embrace this idea and welcome any employee contribution, as long as it is positive of course. More than ever, managing a dental practice is about teamwork.

\section{Fig. 1 The business planning cycle}

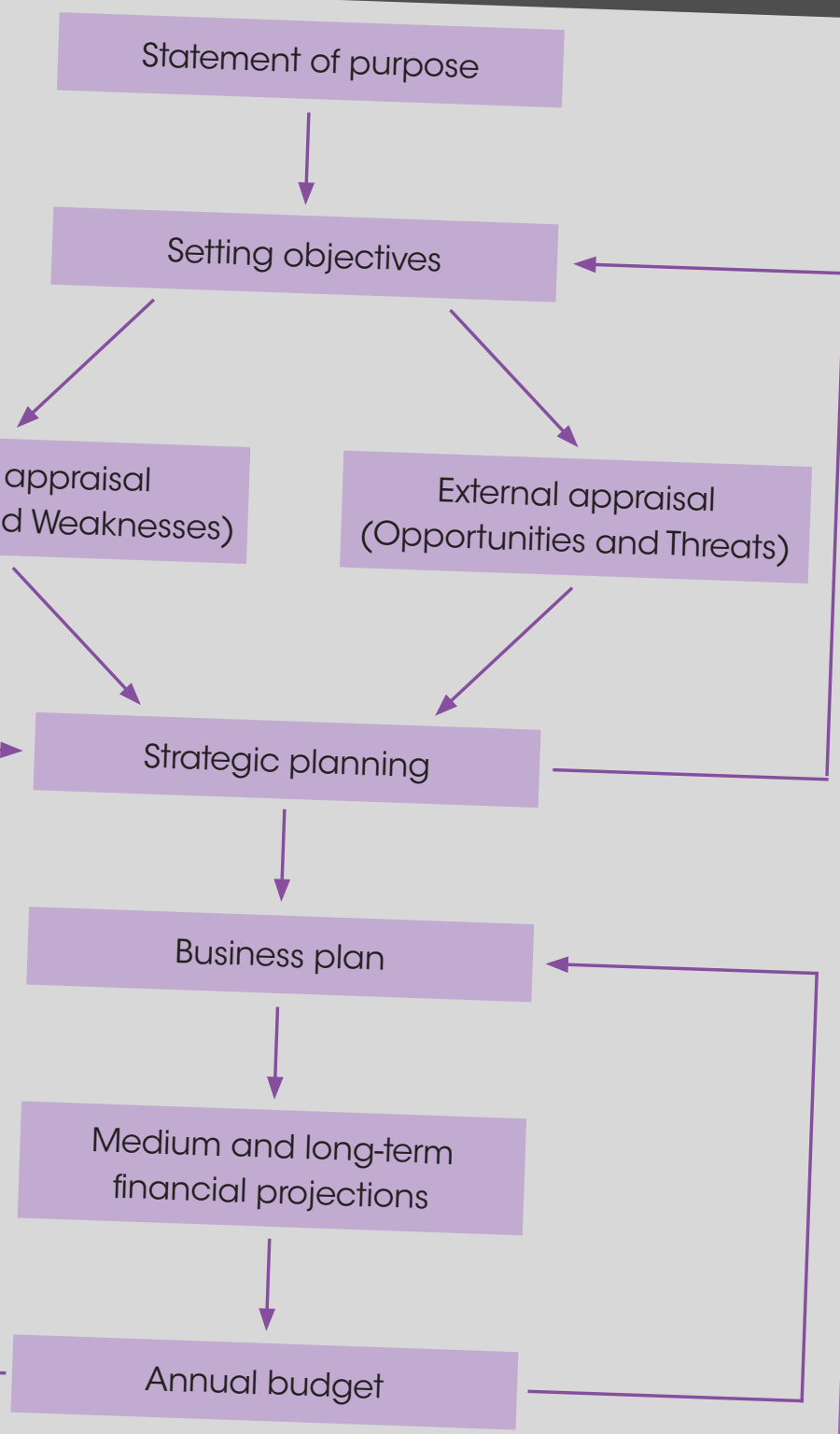

Once I realised the importance of 'context' in history it all started to make much more sense to me. I stopped seeing history as just being dates and people, it became much more about events, why they occurred, and about people's motivation. In the same way, I hope I have shown you why you should dig beneath the surface and look beyond the day-to-day necessities of your role and start to see things in a much broader context. The advent of CQC has now taken away the option of being a passive employee; now everyone has to be manager whether they like it or not. I am a great advocate of personal development and life long learning, and have always believed that anything you learn, no matter how irreverent it might seem at the time, will one day be of use to you. You maybe can't see how writing a business plan can possibly matter to you in your current role, but who knows, one day you might have the urge to manage a dental practice.
'Being aware of the management

\section{process}

and using it

consciously is

the first step

along the road

to becoming

a manager.' 